\title{
Role of HRCT Temporal Bone in Diagnosis of Chronic Suppurative Otitis Media in Correlation with Intraoperative Findings
}

\author{
S. Ranjith Kumar' ${ }^{1}$ V. Priyanka Vudumula ${ }^{1}$, M. Maghiben ${ }^{2}$

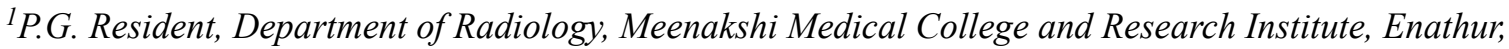 \\ Kanchipuram, Tamilnadu, India, ${ }^{2}$ Assistant Professor, Department of Radiology, Meenakshi Medical College and \\ Research Institute, Enathur, Kanchipuram, Tamilnadu, India
}

\begin{abstract}
This study aims to evaluate the role of preoperative HRCT temporal bone in the diagnosis of the disease, its extension and complications and plan for surgery. The involved structures and also in knowing prognosis is compared with Intraoperative findings made by the surgeon to know its precision in diagnosis. It also helps in diagnosing intracranial complications of CSOM at an early stage and help to plan surgery. Patients presenting/Suspected to have CSOM who were planned for mastoid exploration surgery in Department of ENT, within a period of 2 years-from February 2019 to September 2020, were taken up for study. The patient will undergo HRCT temporal bone with Aquilon 160 slice CT scanner producing sub millimetric thin axial scans Following areas of interest were looked up in preoperative scans:-

- Pneumatization of mastoid

- Tegmen tympani erosion

- Facial canal dehiscence

- Ossicular status

- Extent of disease

- Sinus plate erosion

- Lateral semicircular canal dehiscence

- Disease outside middle ear cleft

Out of total 30 patients of CSOM, $26(52 \%)$ were males. Majority of the patients (70\%) were in the age group of 11 to 30 years. Left ear was involved in $40 \%$ of the patients. Majority of the patients (80\%) presented with chief complaints of otorrhoea. In the present study, External Auditory Canal (EAC) was seen normal in majority of patients (82\%) both radio logically and per operatively. HRCT scan was found to be highly sensitive (100\%) in diagnosing cholesteatoma. CT scans diagnosed erosion of malleus with $100 \%$ sensitivity and specificity and erosion of incus with $91 \%$ sensitivity and $100 \%$ specificity.HRCT has a very high reliability for diagnosis of erosion of scutum, erosion of ossicles and its disruption, Pneumatization of mastoid, anterior lying sigmoid, extent of cholesteatoma in the middle ear and MAC. The study concludes that HRCT can be recommended not just for symptomatic cases but in all suspected cases in knowing the extent of the disease thereby reducing the morbidity.
\end{abstract}

Keywords: Cholesteatoma, Chronic suppurative otitis media, HRCT temporal bone, Middle ear, Otitis media, Otorrhoea investigation, HRCT unsafe ear.

\section{Corresponding Author:}

\section{Maghiben}

Assistant Professor, Department of Radiology,

Meenakshi Medical College and Research Institute,

Enathur, Kanchipuram, Tamilnadu, India

e-mail: maghiben@gmail.com

\section{Introduction}

Chronic otitis media (COM) is the chronic inflammation of the lining formed by mucoperiosteum of the middle ear cleft. Overcrowding, poor socioeconomic status, illiteracy and poor hygiene are all factors, which play an essential role in this disease. The prevalence of COM is around 65 to 330 million people. Over $90 \%$ of 
the burden is borne by lower socio-economic countries, India was found to have the highest prevalence (around $7.8 \%)$.

Chronic otitis media causes persistent foul-smelling ear discharge and leads to conductive hearing loss. The patient can develop intracranial and extracranial complications. Myringoplasty can be performed if there is a dry and inactive perforation for 3 to 6 months. ${ }^{[1]}$

HRCT Temporal bone is a common modality available in diagnosing and knowing the extent of the disease, and can inform the surgeon of its extent, severity, and associated pathologies. It's fairly cheap and easily available. HRCT has proved to be better than plain CT and can visualize areas that cannot be visualized by the endoscope.

The purpose of the study is to compare the diagnostic accuracy of HRCT temporal bone in diagnosing CSOM with its severity, extent and associated pathologies in correlation with the intraoperative findings to know the diagnostic efficacy of HRCT. The study is conducted in the department of Radio-diagnosis for over a period of 2 years. ${ }^{[2]}$

\section{Materials and Method}

This present study entitled "Roleof HRCT Temporal bone in diagnosis of CSOM incorrelation with intra operative findings" is a prospective study done in Meenakshi Medical College \& Research Institute from February 2019 to September 2020. After obtaining approval from the ethical committee this study was done on 30 patients with CSOM. Written informed consent was obtained from patients

Patients with complaints of pain, foulsmelling ear discharge referred from departments of Otorhinolaryngologyto the Department of Radio diagnosis at Meenakshi Medical College Hospital \& Research Institute and are scanned by TOSHIBA PRIME Aquilion 160 Slice Computed Tomography machine by the technique described below ${ }^{[3]}$

\section{Technique:}

- Slice thickness: $0.8 \mathrm{~mm}$

- Reconstruction algorithm: high spatial frequency or "sharp" algorithm

- $\mathrm{kV}(\mathrm{p}) 120$
- $\mathrm{mA}$ less than $80 ; \mathrm{mAs}$

- $\quad$ Scan (rotation) time: as short as possible (e.g., $0.8 \mathrm{~s}$ )

- Scan mode: Spiral mode

- Contrast - None

- Inspiratory level: Not needed

- Position: Supine

- Acquisition: spaced axial imaging

- Reconstruction: Coronal and sagittal

- Window: Window Width $2000 \mathrm{H}$ and Level at $-700 \mathrm{H}$

The parameters compared with intra operative findings are Pneumatisation of mastoid, extent of disease, tegmen tympani erosion, sinus plate erosion, facial canal dehiscence, lateral semicircular canal dehiscence, Ossicular status, disease outside middle ear cleft.

\section{Result}

Table 1: Age distribution

\begin{tabular}{|c|c|c|}
\hline Age in years & Number of patients & Percentage \\
\hline$<10$ & 5 & 16 \\
\hline $11-20$ & 4 & 13 \\
\hline $21-30$ & 8 & 26 \\
\hline $31-40$ & 4 & 13 \\
\hline $41-50$ & 1 & 3 \\
\hline $51-60$ & 4 & 13 \\
\hline $61-70$ & 4 & 13 \\
\hline
\end{tabular}

In this study, it was found that the majority (26\%) of patients were aged between 21-30 years. $16 \%$ aged less than 10 years, $13 \%$ were aged $11-20$ years. $13 \%$ between $31-40$ years. $3 \%$ between $41-50$ years. $16 \%$ between $0-10$ years. $13 \%$ between $51-60$ years. In this study, the mean age was 26.9 years; the youngest patient was 6 years of age and the oldest was 73 years old.

Table 2: Distribution by gender

\begin{tabular}{|l|c|c|}
\hline Sex & Number of patients & Percentage \\
\hline Male & 18 & 60 \\
\hline Female & 12 & 40 \\
\hline
\end{tabular}

In the current study the male to female ratio is $1: 0.6$ 
Table 3: Side of the ear affected

\begin{tabular}{|l|c|}
\hline Side of the ear & Number of patients \\
\hline Right & 14 \\
\hline Left & 16 \\
\hline
\end{tabular}

In this study left side (54\%) is affected more than the right side (46\%)

Table 4: SCUTUM AND EAC involvement in correlation with intraoperative findings

\begin{tabular}{|l|c|c|c|c|}
\hline & \multicolumn{2}{|c|}{ EAC Involvement } & \multicolumn{2}{c|}{ SCUTUM Erosion } \\
\hline Status & $\begin{array}{c}\text { HRCT } \\
\text { Findings }\end{array}$ & $\begin{array}{c}\text { INTRA OP } \\
\text { Findings }\end{array}$ & $\begin{array}{c}\text { HRCT } \\
\text { Findings }\end{array}$ & $\begin{array}{c}\text { INTRA OP } \\
\text { Findings }\end{array}$ \\
\hline Involved & 26 & 26 & 12 & 10 \\
\hline Normal & 4 & 4 & 18 & 20 \\
\hline
\end{tabular}

In the current study, it is found that external auditory canal involvement is detected by HRCT in 26 cases; the intraoperative findings show EAC involvement in 26 cases. The sensitivity and positive predictive value of HRCT in diagnosing EAC involvement is $100 \%$. Specificity $-90 \%$ and negative predictive value is also $100 \%$ (For prevalence of 33\%)

In the current study, it is found that Scutum erosion is detected by HRCT in 12 cases and 18 cases are found to have normal Scutum, The intraoperative findings show Scutum involvement is seen in 10 cases and 20 cases are found to have normal Scutum. The sensitivity of HRCT in diagnosing Scutum involvement is $96 \%$, specificity is $80 \%$ with a positive predictive value of $96 \%$ (For prevalence of $83 \%$ ). However, 2 cases $(6 \%$ ) show the false-positive result in HRCT.

Table 5: Ossicles erosion in correlation with intraoperative findings

\begin{tabular}{|l|c|c|}
\hline Ossicles erosion & HRCT findings & $\begin{array}{c}\text { Intraoperative } \\
\text { findings }\end{array}$ \\
\hline Normal & 11 & 12 \\
\hline Mildly eroded & 10 & 10 \\
\hline Severely eroded & 9 & 8 \\
\hline Total & $\mathbf{3 0}$ & $\mathbf{3 0}$ \\
\hline
\end{tabular}

In the current study, Ossicular involvement is detected by $\mathrm{CT}$ and are categorized into mild and severe erosions based on number and parts of ossicles involved

In current HRCT study, 11 cases have normal ossicles, 10 cases have mild Ossicular erosions (with the sensitivity of $100 \%$ and positive predictive value of $100 \%$ ) and 9 cases have severe Ossicular erosions. Intraoperatively it is found 12 cases have normal ossicles, 10 cases have mild erosion and 8 cases have severe erosions (with the sensitivity of $100 \%$ and positive predictive value of $100 \%$ ), however, there is one false positive in detecting severe erosion.

\section{Table 6: Dural plate erosion in correlation with intraoperative finding}

\begin{tabular}{|l|c|c|}
\hline Dural Plate & HRCT Findings & INTRA OP \\
\hline Normal & 27 & 26 \\
\hline Eroded & 3 & 4 \\
\hline Total & $\mathbf{3 0}$ & $\mathbf{3 0}$ \\
\hline
\end{tabular}

In the current study, it is found that for $30 \%$ prevalence, sensitivity is $99.4 \%$ and specificity is $100 \%$ with PPV of $100 \%$ and NPV of $99.9 \%$ HRCT detected dural plate involvement in 3 cases and 27 cases were found to be normal. Intraoperatively 4 cases had dural plate involvement and 26 cases were found to be normal.

Table 7: Tegmen tympani erosion in correlation with Intra op findings

\begin{tabular}{|l|c|c|}
\hline Tegmen Status & HRCT Findings & $\begin{array}{c}\text { INTRA OP } \\
\text { Findings }\end{array}$ \\
\hline Normal & 24 & 25 \\
\hline Mildly eroded & 3 & 2 \\
\hline Completely eroded & 3 & 3 \\
\hline Total & $\mathbf{3 0}$ & $\mathbf{3 0}$ \\
\hline
\end{tabular}

In current study it is found that for prevalence of $17 \%$, sensitivity is $100 \%$, specificity is $96 \%$, $\mathrm{PPV}$ is $83 \%$ and negative predictive value is $100 \%$. HRCT detected tegmen involvement in six cases and 24 cases were found to be normal. Intraoperatively five cases had tegmen involvement and 25 cases were found to be normal. HRCT detects mild tegmen tympani involvement with $75 \%$ sensitivity. There is a $100 \%$ sensitivity of HRCT in detecting complete tegmen erosion. 
Table 8: Facial nerve canal erosion and Lateral semi circular Canal status in correlation with intraoperative finding

\begin{tabular}{|l|c|c|c|c|c|}
\hline Facial canal & HRCT findings & $\begin{array}{c}\text { Intraoperative } \\
\text { findings }\end{array}$ & $\begin{array}{c}\text { Lateral semicircula } \\
\text { canal }\end{array}$ & HRCT finding & $\begin{array}{c}\text { Intraoperative } \\
\text { findings }\end{array}$ \\
\hline Normal & 25 & 25 & Normal & 28 & 28 \\
\hline Eroded & 5 & 5 & Eroded & 2 & 2 \\
\hline Total & $\mathbf{3 0}$ & $\mathbf{3 0}$ & Total & $\mathbf{3 0}$ & $\mathbf{3 0}$ \\
\hline
\end{tabular}

In current study it is found that for prevalence of 17 $\%$, the sensitivity is $100 \%$, specificity is $100 \%$, PPV is $100 \%$ and negative predictive value is $100 \%$. HRCT detected facial canal involvement in 5 cases and 25cases were found to be normal. Intraoperatively 5 cases had facial canal involvement and 25 cases were found to be normal. HRCT detects facial canal involvement with $100 \%$ sensitivity and with $100 \%$ positive predictive value.

In current study it is found that for prevalence of $6.7 \%$, the sensitivity is $100 \%$, specificity is $100 \%$, PPV is $100 \%$ and negative predictive value is $100 \%$. HRCT detected lateral semicircular canal involvement in 2 cases and 28 cases were found to be normal. Intraoperatively 2 cases had facial canal involvement and 28 cases were found to be normal. HRCT detects lateral semicircular canal involvement with $100 \%$ sensitivity and $100 \%$ positive predictive value.

Table 9: Mastoid status in correlation with intraoperative findings

\begin{tabular}{|l|c|c|}
\hline Mastoid Status & $\begin{array}{c}\text { HRCT } \\
\text { Finding }\end{array}$ & $\begin{array}{c}\text { INTRA OP } \\
\text { Findings }\end{array}$ \\
\hline Normal & 2 & 3 \\
\hline Soft tissue density lesion & 12 & 13 \\
\hline Sclerosed & 16 & 14 \\
\hline Total & $\mathbf{3 0}$ & $\mathbf{3 0}$ \\
\hline
\end{tabular}

In current study it is found that for prevalence of $90 \%$, the sensitivity is $100 \%$, specificity is $66.7 \%$, PPV is $96 \%$ and negative predictive value is $100 \%$.

HRCT detected 2 cases with normal mastoid air cells, 12 cases with soft tissue density lesion and 16 cases had sclerosed partially pneumatized mastoid air cells. Intraoperatively 3 cases were found to have normal mastoid, 13 cases with exudate infiltration in the mastoid and 14 cases were found to have partially pneumatized sclerosed mastoid.

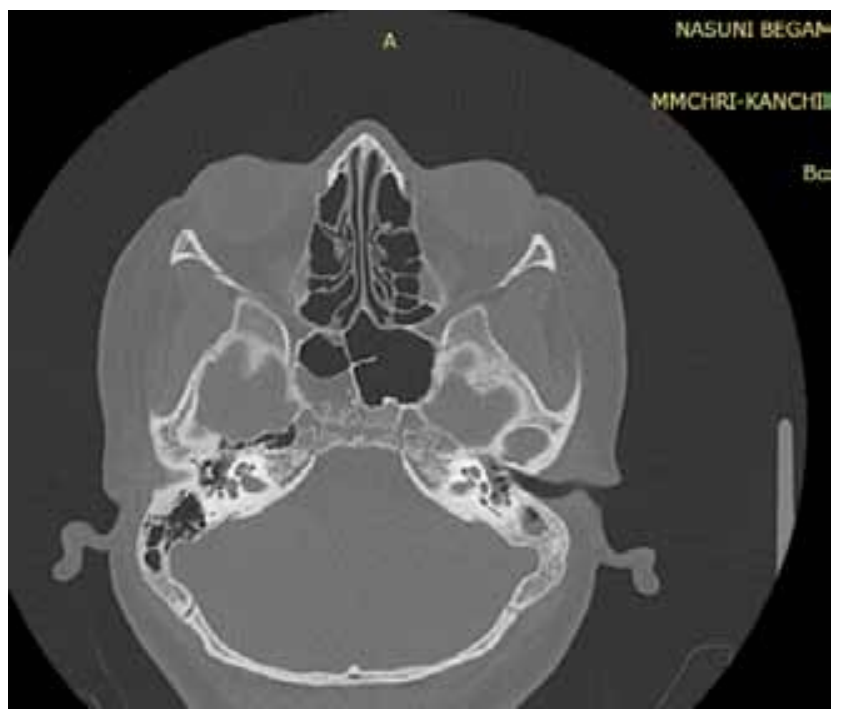

(a)

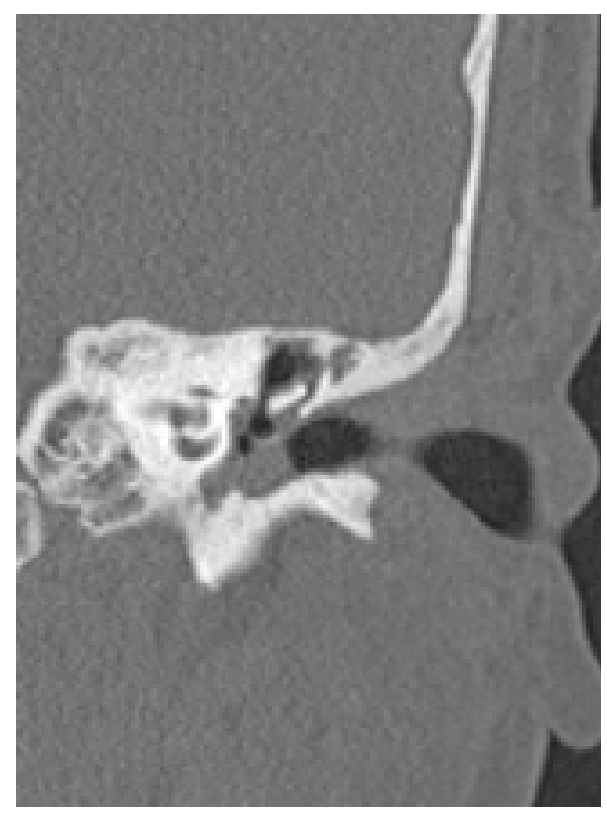

(b)

Fig 1: a) Axial section showingsoft tissue granulation tissue in epitympanum, mesotympanum and hypotympanum. b) Same findings seen in coronal section 

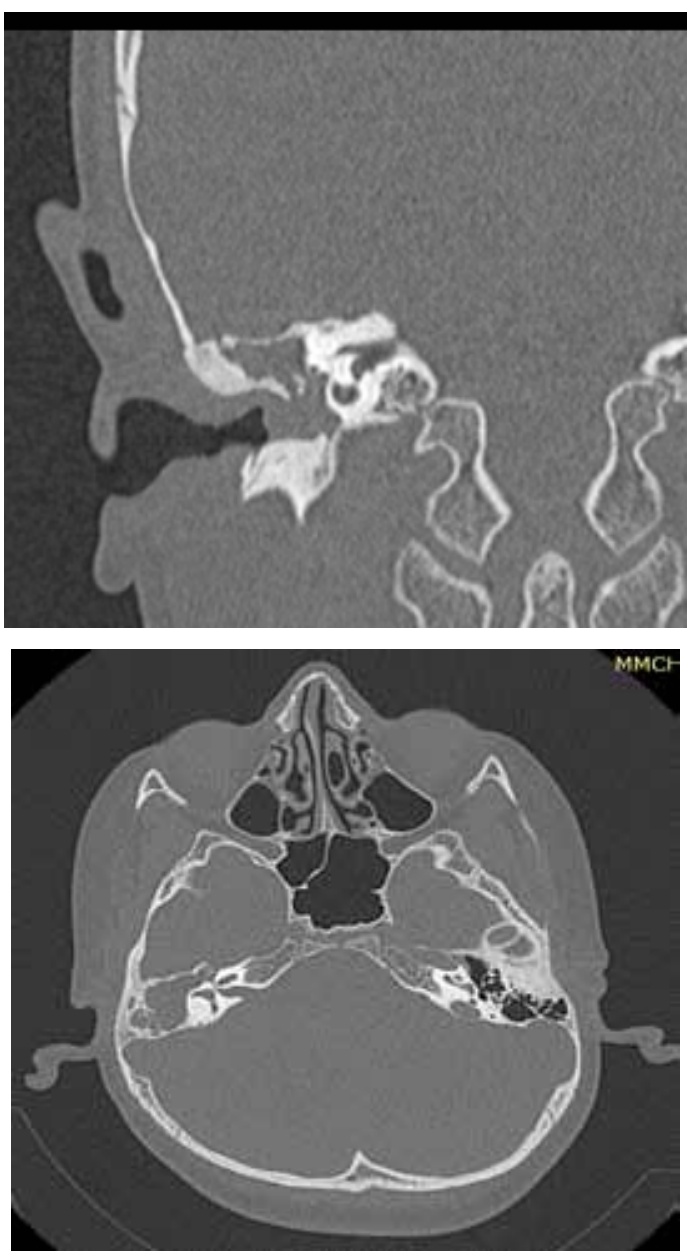

Fig 2: Heterodense soft tissue lesion with in the tympanic cavity (mesotympanum, epitympanum) and mastoid antrum causing erosion of walls tympanic cavity, scutum, tegmen tympani, ossicles $\&$ mastoid antrum on right side

\section{Discussion}

In this study, a total number of 30 patients were selected randomly. The maximum number of patients were in the 21-30 age group ( $3^{\text {rd }}$ decade of life) this is in consistence with Gerami etal(2009) ${ }^{[3]}$ claims that average age of CSOM is 35.1 years. There is more variation in children. The gender radio was which is 1:0.6.More than $90 \%$ patients belonged to low socioeconomic status. Lack of hygiene is one of the causes for CSOM. Left side $(54 \%)$ is affected more than the right side (46\%). From the clinical data obtained from the Department of Otorhinolaryngology, $64 \%$ of patients had AAD and the remaining $36 \%$ had TTD. Mastoid was found to be well pneumatized (normal) in 9\% cases, $43 \%$ cases had soft tissue density lesion in CT (suggestive active infection) and $48 \%$ patients had sclerosed mastoid with improper pneumatization. In the case of Mastoid air cells, HRCT has $100 \%$ sensitivity and specificity was $66.7 \%$ which is similar to Gerami $\mathrm{H}$ et al (2009) ${ }^{[3]}$.HRCT is $100 \%$ sensitive and $66.7 \%$ specific in detecting soft tissue density lesions. However, HRCT is less sensitive in differentiating cholesteatoma from a granulation tissue for which MRI has a better diagnostic role. There is 100 $\%$ sensitivity in detecting cholesteatoma in Prussacks space, this is in consistence with Ranga Reddy Siliguri et al $(2011)^{[4]}$ but there is $90 \%$ specificity which is slightly higher than the study conducted by Ranga Reddy Siliguri et al $(2011)^{[4]}$. Bony erosion is diagnosed by HRCT in the presence of cholesteatoma in $100 \%$ cases this is in consistence with Jacker et al $(1984)^{[5]}$ who found $98 \%$ in their cases. HRCT detected ossicle erosion in all cases, there is usually some degree of subjective variation when reporting the grade of ossicular erosion, however, irrespectively of grading, cases reported to have any degree ossicular erosion had erosions intraoperatively. This is in consistence with Zhang $X$ et al (2004) ${ }^{[6]}$ and Chee NW et al (2001) ${ }^{[7]}$.In this study, there was facial canal involvement in 5 cases, with a sensitivity of intraoperatively of $100 \%$ which is similar to the result obtained byFiras Q Alzoubi et al (2008) ${ }^{[8]}$ and Chee NW et al (2001) ${ }^{[7]}$. RCT for Lateral semicircular canal involvement in 2 cases and 28 were found to have normal lateral semicircular canal with $100 \%$ sensitive and $100 \%$ specificity. Similar results were found byFiras Q Alzoubi et al. (2008) $)^{[8]}$ and Gyanu et al ${ }^{[9]}$. HRCT was found to be fairly sensitive in detecting Tegmen erosion which agrees with results by Jackler RK (1984) ${ }^{[5]}$ and Gerami H et al. (2009) ${ }^{[3]}$

\section{Conclusion}

HRCT has a very high reliability for diagnosis of erosion of scutum, erosion of ossicles and its disruption, Pneumatization of mastoid, anterior lying sigmoid, extent of cholesteatoma in the middle ear and MAC, It also helps in detecting presence of complications like mastoiditis, abscess, dehiscence of mastoid cortex, erosion of sigmoid plate, facial canal dehiscence, labyrinthine fistula and intracranial complications .

$\mathrm{COM}$ can at times be life-threatening when it's associated with intracranial complications that warrant the ENT surgeons to be familiar with standard approaches in surgeries. The use of HRCT and advances in radiological imaging had improved the study of the temporal bone in cases of CSOM in diagnosing the disease, knowing its extent and associations, anatomical and neurological structure involved. Therefore the study 
concludes that HRCT can be recommended not just for symptomatic cases but in all suspected cases in knowing the extent of the disease thereby reducing the morbidity.

\section{Ethical Clearance: Nil}

Source of Funding: Meenakshi Academy of Higher Education and Research, Chennai, India

Conflict of Interest: Nil

\section{References}

1. Mittal R, Lisi C V., Gerring R, Mittal J, Mathee $K$, Narasimhan G, et al. Current concepts in the pathogenesis and treatment of chronic suppurative otitis media. J Med Microbiol. 2015;64(10):110316.

2. Majeed J, Sudarshan Reddy L. Role of CT Mastoids in the Diagnosis and Surgical Management of Chronic Inflammatory Ear Diseases. Indian $\mathrm{J}$ Otolaryngol Head Neck Surg. 2017;69(1):113-20.

3. Gerami H, Naghavi E, Wahabi-Moghadam M, Forghanparast K, Akbar MH. Comparison of preoperative computerized tomography scan imaging of temporal bone with the intra-operative findings in patients undergoing mastoidectomy. Saudi Med J. 2009 Jan 1;30(1):104-8.
4. Sirigiri RR, Dwaraknath K. Correlative study of HRCT in attico-antral disease. Indian Journal of Otolaryngology and Head \& Neck Surgery. 2011 Apr 1;63(2):155-8.

5. Jackler RK, Dillon WP, Schindler RA. Computed tomography in suppurative ear disease: a correlation of surgical and radiographic findings. The Laryngoscope. 1984 Jun;94(6):746-52.

6. Si Y, Zhang ZG, Chen SJ, Zheng YQ, Chen YB, Liu Y, Jiang H, Feng LQ, Huang X. Attenuated TLRs in middle ear mucosa contributes to susceptibility of chronic suppurative otitis media. Human immunology. 2014 Aug 1;75(8):771-6.

7. Chee NW, Tan TY. The value of pre-operative high resolution CT scans in cholesteatoma surgery. Singapore Med J. 2001;42(4):155-9.

8. Alzoubi FQ, Odat HA, Al-Balas HA, Saeed SR. The role of preoperative CT scan in patients with chronic otitis media. Eur Arch Oto-RhinoLaryngology. 2009;266(6):807-9.

9. Gyanu J, Modwal A, Saboo R, Saxena G, Sapra G. A Study of the Correlation of the Clinical Feature, Radiological Evaluation and Operative Finding in CSOM with Cholesteatoma. 2014;2:3259-69. 